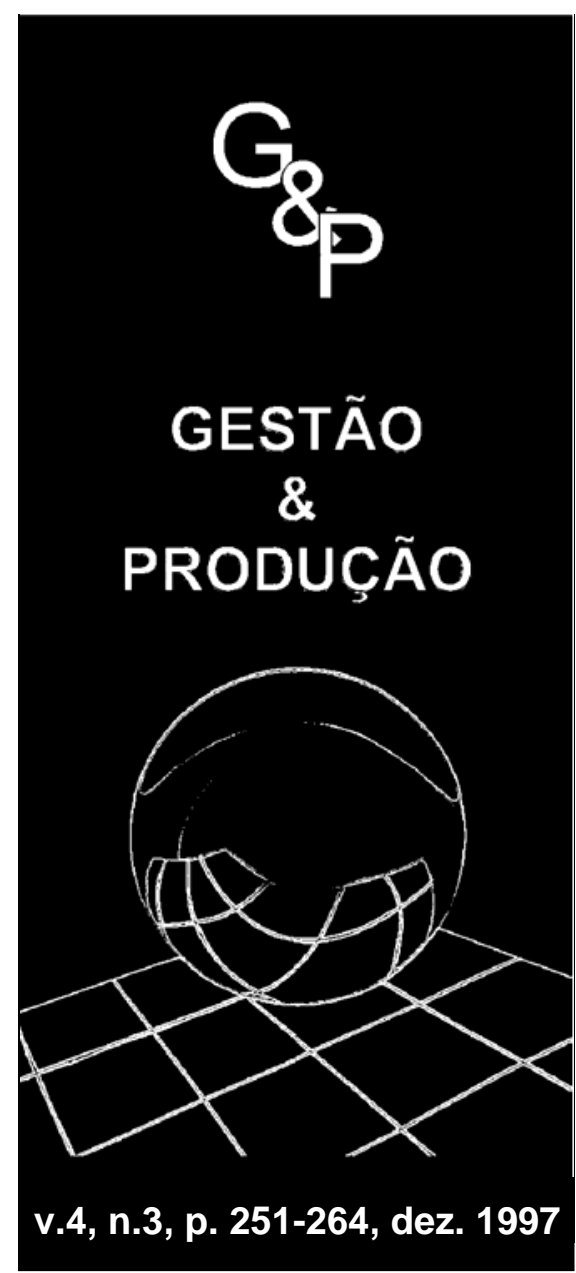

\section{DICAST: UM SISTEMA INTELIGENTE PARA AUXÍLIO AO PROJETO DE PEÇAS FUNDIDAS}

\begin{abstract}
Ricardo M. Naveiro
Prof. Doutor do Depto. de Engenharia Mecânica da E.E. / UFRJ e do Programa de Engenharia de Produção da COPPE / UFRJ Caixa Postal 68507 - Centro de Tecnologia Cidade Universitária - 21945-970 - Rio de Janeiro / RJ email: ricardo@pep.ufrj.br

Peter O'Grady Professor and Chair - Industrial Engineering The University of lowa 4132 Engineering Bldg. lowa City, lowa 52242-1527, USA email: pjogrady@icaen.uiowa.edu
\end{abstract}

\title{
Resumo
}

Este artigo aborda a questão da integração das atividades de projeto e manufatura, descrevendo um sistema de engenharia desenvolvido para auxiliar os projetistas na etapa de projeto detalhado de peças fundidas. O projetar é considerado como uma atividade sujeita a restrições, que condicionam a tomada de decisão. Nesse sentido, o processo de projetar uma peça fundida pode ser modelado como um conjunto de variáveis que representam os parâmetros do projeto interconectados por restrições. Quando alguma restrição não é atendida o sistema se encarrega de avisar ao projetista, indicando qual restrição não foi atendida e as causas prováveis do não atendimento.

\section{Palavras-chave: projeto para manufatura, engenharia concorrente, programação lógica sob restrições, sistemas inteligentes de auxílio ao projeto.}

\section{Introdução}

$\mathrm{E}$ xistem vários pontos de vista que definem o que é projeto, cada um depende da formação e da experiência profissional de quem está opinando. Uma definição bem difundida é a de que projeto é uma atividade que produz uma descrição de algo que ainda não existe, porém capaz de viabilizar a construção desse artefato em criação. Na língua inglesa o termo design refere-se tanto ao resultado quanto à ação de projetar, enquanto em português o termo projetação é o mais adequado para denominar o "ato de projetar". A projetação deve ser entendida como uma 
progressão na qual a incerteza diminui à medida que se evolui em direção da solução. Nessa progressão a matéria-prima envolvida é a informação, que vai se transformando ao longo da mesma.

Pesquisadores das ciências cognitivas e membros da comunidade da área de Inteligência Artificial tratam o projeto como uma atividade de "resolução de problemas", prática que compreende um conjunto de heurísticas que explicita os processos cognitivos usados pelo arquiteto, engenheiro ou designer. Nesse caso, os problemas principais envolvidos são: como explicitar e representar o conhecimento utilizado pelo projetista para estruturar especificações incompletas de projeto (GOEL \& PIROLLI, 1989). Dentro dessa linha de abordagem destacamos algumas das propostas de definição de projeto contidas em documento da National Science Foundation (MILES \& MOORE, 1994):

projeto é um processo de tomada de decisão.

projeto é uma atividade de resolução de problemas.

projeto é um processo de planejamento e busca.

projeto é um processo de satisfação de restrições.

Todas essas definições se concentram na atividade intelectiva do ato de projetar, enquadrando-a na categoria genérica das atividades intelectuais que têm um objetivo racional a ser alcançado. Nesse aspecto, não há diferença fundamental entre um diagnóstico médico e o projeto de uma casa (NEWELL \& SIMON, 1969).

A área de Sociologia da Inovação é uma outra abordagem que conceitualiza projeto. Considera-o como sendo um processo social de construção do artefato no qual o resultado é maior do que a soma ou síntese das contribuições individuais dos participantes. Nessa linha de pensamento o projeto é um processo coletivo viabilizado pela organiza- ção que o sustenta e os problemas principais envolvidos são: criação de um ambiente para o trabalho intelectual cooperativo, gerenciamento e controle do estado da informação, compartilhar informação de conteúdo adequado e no tempo correto, etc. Essa abordagem considera que a identificação das diversas tarefas do projeto e sua inserção como constituintes do todo define as fronteiras entre as diversas etapas do projeto, bem como a relação entre os participantes. As definições a seguir privilegiam $\mathrm{o}$ aspecto de trabalho coletivo contido na atividade de projetar artefatos:

projeto é um processo interativo.

projeto é uma atividade criativa e inexplicável.

projeto é um processo paralelo.

Pode-se sintetizar essas duas vertentes em duas caracterizações complementares sobre o que é projeto. A primeira privilegia o aspecto coletivo da criação de um artefato, enfatizando as questões que vêm à tona quando se tem uma equipe trabalhando em aspectos particulares de um objetivo comum. A outra se concentra na atividade individual de criação que se processa com cada membro de uma equipe ao projetar.

A perspectiva coletiva na projetação considera quatro aspectos fundamentais como constituintes do projeto: a organização, os contextos, os condicionantes e o discurso (BUCCIARELLI, 1988). A organização das atividades de um projeto é algo definido ao longo da progressão do projeto e sua definição estabelece as fronteiras entre as tarefas do projeto, bem como a relação entre seus participantes. Os contextos são melhor definidos como sendo os universos de competências, isto é, ambientes de especialização técnica com dialetos e símbolos próprios. Os condicionantes do projeto são as especificações e as restrições que balizam os diversos constituintes do projeto. $\mathrm{O}$ atendimento às restrições é feito por meio de negociação e contingenciamento entre os 
membros da equipe, o que exige um discurso de comunicação capaz de conectar universos de competência diversos. Por fim, o discurso é a linguagem desenvolvida para reconciliar os diversos contextos e é exercido sobretudo ao nomear os elementos constituintes do artefato. Essas categorias de informação que povoam a progressão do projeto definem os tipos mais adequados de auxílio informatizado ao projeto que devem ser utilizados para um melhor desempenho da equipe responsável pelo mesmo (NAVEIRO, 1997).

Na perspectiva individual de abordar a projetação deve-se considerá-la como pertencente à classe dos problemas abertos, isto é, uma classe em que os condicionantes não são capazes de delimitar inteiramente o espaço de soluções (HINRICKS, 1992). Isso exige do projetista um esforço para diminuir o número de graus de liberdade na procura de uma solução; o que na prática representa um trabalho de estruturação do problema à medida que ocorre a progressão do projeto. A projetação pode ser explicada pela atividade de "busca de soluções" que se dá por meio de uma série de mecanismos cognitivos tais como: decomposição, associação, analogia, prototipagem, etc. (AKIN, 1986). $\mathrm{Na}$ perspectiva individual da projetação é muito importante a existência do desenho como elemento de trabalho capaz de sintetizar o ato criativo do projetista. $\mathrm{O}$ registro, em um meio artificial qualquer, de uma das várias soluções possíveis para o projeto permite ao projetista liberar sua memória de curta duração para a geração de outras alternativas (WOODBURY, 1987). A perspectiva individual da projetação associada a criação de soluções viáveis trabalha intensamente com o desenho e com o conhecimento, de forma que cada alternativa gerada incorpora na representação gráfica o conhecimento do projetista sobre o assunto em questão.

\section{Engenharia Concorrente ou Simultânea}

Engenharia Concorrente é uma
maneira de conduzir a atividade de
projeto de forma que as várias atividades relacionadas à progressão do projeto sejam integradas e realizadas, sempre que possível, em paralelo ao invés de seqüencialmente. Mais especificamente, "Engenharia Concorrente é a consideração, durante a fase de projeto, dos fatores associados ao ciclo de vida do produto. Eles incluem fabricação, montagem, teste, manutenção, custo e qualidade” (O’GRADY \& YOUNG, 1991). A chave para a implantação da Engenharia Concorrente é alcançar o mais cedo possível a integração do conhecimento prático da empresa na atividade de projetar um produto. A
Engenharia Concorrente é universalmente aceita como pertencente à esfera do projeto, e seu uso pode economizar muito dinheiro evitando os custos adicionais decorrentes de mudanças de engenharia que aparecem a jusante da progressão do projeto (NAVEIRO \& O'GRADY, 1995). Zangwill relata que, para o computador AS/400 da IBM uma mudança ocorrida na fase de testes custou em média treze vezes mais que mudanças implementadas nos estágios iniciais do projeto (ZANGWILL, 1992). A figura 1 mostra os diversos fluxos de informação presentes na progressão do projeto e a abordagem da Engenharia Concorrente no gerenciamento dessa informação. 


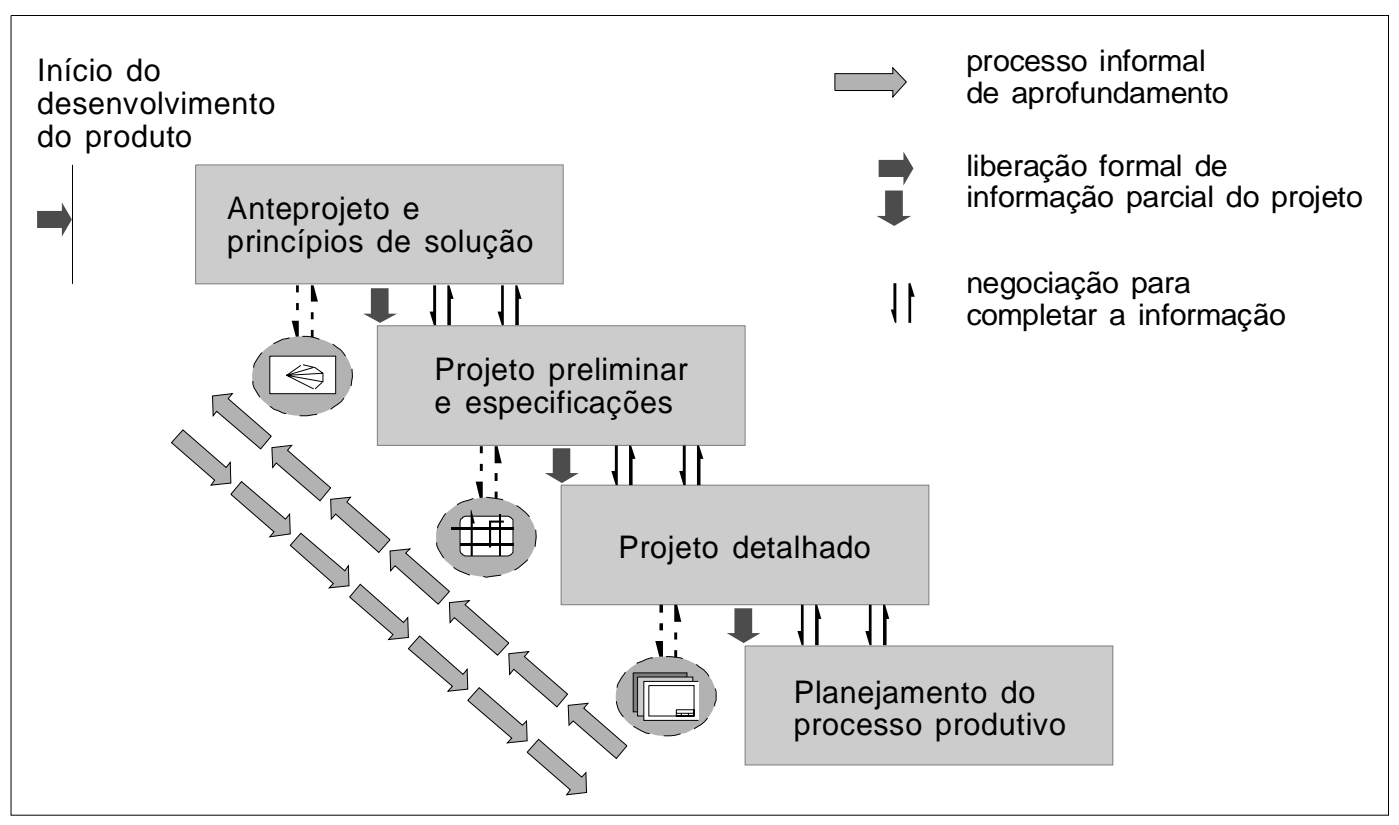

Figura 1 - Engenharia Concorrente

Existem duas abordagens básicas para implementar a prática da Engenharia Concorrente: grupo de projeto e sistemas computacionais (PARSAEI \& SULLIVAN, 1993). Na realidade, essas duas abordagens não são incompatíveis; ao contrário, o desempenho do grupo de projeto é realçado pelo auxílio computacional, possibilitando aos projetistas considerar vários aspectos do ciclo produtivo no instante do projeto. A abordagem coletiva da projetação consiste em juntar um grupo de especialistas de todos os setores que contribuem para a realização do projeto do produto de forma a viabilizar a criação coletiva.

A principal técnica gerencial adotada nessa abordagem é a superposição de tarefas, executando ao mesmo tempo atividades que antes seriam realizadas de modo seqüencial. A implementação desse princípio se verifica pela liberação de documentação parcial do projeto para os membros da equipe que trabalham "a jusante”, de forma a permitir que eles façam avaliações preliminares do que se passa desde as etapas iniciais do projeto. Whitney relata que esse procedimento de "superposição de etapas” é largamente utilizado na indústria automobilística japonesa e sua implementação se dá de uma maneira formal, sendo que cada participante da equipe tem consciência do conteúdo de informação a ser liberado antecipadamente (WHITNEY, 1994). De fato, a identificação das tarefas, bem como sua identificação como constituintes do todo define as fronteiras entre as tarefas e, em conseqüência, a relação entre os participantes.

A informação parcial liberada faz parte do discurso do projeto e é definida pela reconciliação entre os universos de especialização dos participantes e pela concordância na denominação das peças do produto e na definição de suas funções.

A organização das atividades de projeto em equipes multidisciplinares vem sendo largamente difundida na indústria, porém apresenta algumas dificuldades para sua implementação. A tomada coletiva de decisões pode ser difícil e o gerenciamento de um grupo de especialistas pode ser complicado, além dos custos que são incorridos na manutenção de uma equipe de alta qualificação concentrada num único projeto. Além disso, há mais dois inconvenientes na manutenção de uma equipe. Em 
primeiro lugar, o envolvimento do especialista ao longo do projeto não é uniforme, o que acarreta no gerenciamento da alocação parcial de pessoal; fato que é sempre complicado de gerenciar em grandes empresas. Um segundo aspecto a considerar são as mudanças que estão em curso no ambiente industrial, onde se verifica a maior participação de fornecedores e de terceiros trabalhando dentro de uma condição de parceria com a empresa contratante. A base de fornecedores das empresas vem se reduzindo e os fornecedores vêm ampliando sua presença junto ao fabricante participando da equipe de projeto como membro efetivo. Clausing relata que a XEROX reduziu sua base de fornecedores de 3000 para 400 e os remanescentes passaram a ser tratados como membros do time de projeto da empresa (CLAUSING, 1989). Nesse caso, as barreiras geográficas existentes entre os membros da equipe aumentam as dificuldades de coordenação do grupo.

A abordagem computacional engloba um conjunto de ferramentas que assistem ao projetista na sua relação com os variados ambientes de especialização técnica com os quais ele tem de lidar ao projetar um artefato. O auxílio computacional serve tanto como elemento capaz de viabilizar a representação gráfica de formas complexas com rapidez, como um meio de registro de um conceito preliminar para posterior refinamento.

No passado, a tecnologia de computação foi uma poderosa ferramenta para lidar com dados, enquanto nos dias de hoje o esforço principal da ciência da computação está concentrado no gerenciamento do conhecimento; situação em que as formas de conhecimento expressas por fórmulas, regras, restrições, compatibilidades, etc. podem ser representadas e participar de operações e cálculos juntamente com os dados (LIAU, 1994).

Os sistemas computacionais de apoio ao projeto estão sendo desenvolvidos para representar e manipular o conhecimento projetual necessário à concretização de um determinado projeto. Existem vários tipos de conhecimento projetual tais como forma geométrica, padrões de projeto da empresa, procedimentos, regras, etc., e a arquitetura do sistema de apoio deve ser capaz de dar conta dessa diversidade de informações.

Inicialmente foram utilizados sistemas especialistas a base de regras para auxiliar o projetista na resolução das diversas relações (muitas vezes conflitantes) existentes entre os parâmetros dos projetos e no processamento das diversas operações lógicas e aritméticas envolvidas. Essa abordagem resultou em arquiteturas de baixa complexidade, porém apresentando a desvantagem de processarem as soluções por caminhos fixos de raciocínio - situação que não se encaixa na atividade de projetação, além de não explicitar adequadamente as influências mútuas que os parâmetros de projeto exercem uns sobre os outros.

No sentido de ultrapassar essas dificuldades e limitações impostas pelos sistemas especialistas a base de regras, começaram a ser desenvolvidos sistemas a base de "lógica de restrições” nos quais as relações entre as diversas características do produto a ser projetado passaram a ser representadas como variáveis sujeitas a restrições.

De fato, a projetação pode ser entendida como um processo de negociação das soluções possíveis que satisfaçam as restrições estabelecidas dinamicamente ao longo da progressão do projeto. Assim, o processo de projetar pode ser representado por um conjunto de variáveis que representam os parâmetros do projeto interconectadas por um conjunto de restrições.

$\mathrm{O}$ ato de selecionar e atribuir valores às variáveis pode ser feito pela combinação de projetista e sistema computacional, incluindo os projetistas como parte do mecanismo de inferência. O uso do conhecimento do projetista na busca por soluções viáveis 
acentua a eficiência computacional comparando-a com sistemas automatizados.

Algumas linguagens a base de restrições foram desenvolvidas para resolver o "problema de satisfação de restrições” para algumas classes de aplicações. Essas linguagens são basicamente declarativas, o que facilita a modelagem dos problemas; seus algoritmos de solução são invisíveis para o usuário que não precisa conhecê-los para a obtenção de uma solução do seu problema. Elas podem representar atributos numéricos, atributos simbólicos e restrições, assim como representar as relações existentes entre eles. Foram desenvolvidos vários sistemas para diversas aplicações tais como: projeto de sistemas elétricos, problemas de seqüenciamento, projeto de sistemas mecânicos, configuração de produtos e genética molecular.

A aplicabilidade de sistemas a base de restrições em Engenharia Concorrente deriva da capacidade de seu mecanismo de inferência ser omni-direcional e da aceitação da interferência do projetista na solução do “problema de satisfação às restrições”. O sistema espera pela atribuição de valores a uma ou mais variáveis, investiga se o valor atribuído pode ser propagado e verifica a consistência no atendimento às restrições. Esse procedimento é fundamental para harmonizar a interface computacional com o mecanismo interno de raciocínio do projetista.

\section{O Projeto de Peças Fundidas}

adequação do projeto do produto à
sua fabricação é uma atividade
desenvolvida na etapa de projeto detalhado, na qual o projetista verifica a conveniência de determinado processo para a fabricação do componente projetado e compatibiliza seu projeto com as facilidades de manufatura existentes na empresa.

No caso de peças fundidas, as facilidades de produção geralmente não se encontram dentro da empresa, uma vez que as indústrias encomendam as peças para fundições, que trabalham na condição de fornecedores da empresa contratante. A seqüência usual de fabricação de uma peça fundida é a seguinte:

- O cliente manda um desenho para a fundição;

- A fundição prepara uma cotação e sugere pequenas modificações no projeto de forma a facilitar a sua fabricação $e$ diminuir seu custo;

- O pedido de fornecimento da peça é colocado na fundição que inicia a preparação do modelo e caixas de macho;
- A fundição prepara um desenho do modelo que é enviado para a seção de modelagem para fabricação;

- A fundição inicia a produção das peças, que são inspecionadas e testadas. Se aparecerem problemas, poderá ser necessário modificar a peça e conseqüentemente o modelo e caixa de macho já fabricados.

Esse procedimento, etapa por etapa, toma muito tempo, pois quando a fundição manda uma cotação com sugestões de modificações o cliente pode não concordar e o processo retorna ao início. Essas três etapas iniciais podem ser reduzidas a uma única se o projetista puder considerar alguns dos fatores de fundição quando ainda estiver projetando a peça, evitando dessa forma um processo de avaliação que só se realizaria após o projeto da peça estar completo.

Em geral, a avaliação da manufaturabilidade é baseada na experiência acumulada na fundição. Os principais pontos são a identificação de aspectos da peça projetada que são difíceis de fabricar, aspectos que podem resultar em defeitos de fundição ou aspectos 
que não se adequam aos padrões da empresa. Normalmente, muito conhecimento empírico é usado para identificar esses aspectos, bem como recomendar modificações que irão corrigir os problemas potenciais. Parte desse conhecimento pode ser formalizado como padrão da empresa e incorporado aos procedimentos standard adotados pelo setor de engenharia. É exatamente isso que os japoneses estão fazendo. Whitney relata que um grande número de empresas japonesas está formalizando todo o processo de criação do produto e guardando em sistemas computa- cionais toda a prática interna de projeto (WHITNEY, 1993).

Pode-se dividir a avaliação da manufaturabilidade de uma peça em três grupos principais: procedimentos gerais, procedimentos específicos e procedimentos para análise da solidificação. Os primeiros estão relacionados à tecnologia de fundição, os segundos retratam as recomendações técnicas relativas a características geométricas específicas das peças, enquanto os últimos se referem aos métodos para a análise da solidificação da peça no molde.

\subsection{Procedimentos Gerais}

O processo de fundição produz as formas geométricas mais complexas, que dificilmente poderiam ser feitas por outros processos de conformação. A forma geométrica é fortemente dependente dos tipos de processos de fundição que estão sendo usados, mas existem algumas recomendações gerais para projetar peças fundidas que são aproximadamente comuns a todos os processos. Essas recomendações gerais dizem respeito à forma geométrica aproximada expressando algumas das restrições que os processos de fundição impõem ao projeto. Destaca-se os seguintes: simplificar a forma geométrica do fundido usando perfis regulares; dividir os fundidos muito complicados em partes separadas;

eliminar os elementos com grande concentração de massa;

usar formas geométricas que facilitem a contração;

evitar o uso de cantos vivos e várias junções no mesmo ponto.

\subsection{Avaliação da Solidificação}

Durante a solidificação a maioria das ligas metálicas se contrai reduzindo seu volume. Para que não se formem vazios na peça, é necessário que haja metal fluindo entre as diversas seções que a compõem. A taxa de resfriamento dos diversos pontos da peça vai definir se haverá formação de vazios ou não. Um método prático para verificar se a peça vai ser preenchida por completo pelo metal é o proposto por Wlodaver (WLODAVER, 1966), que se utiliza da relação existente entre os módulos de solidificação de duas seções adjacentes como estimativa do diferencial de tempo de solidificação entre as duas seções. O módulo de solidificação é definido como:

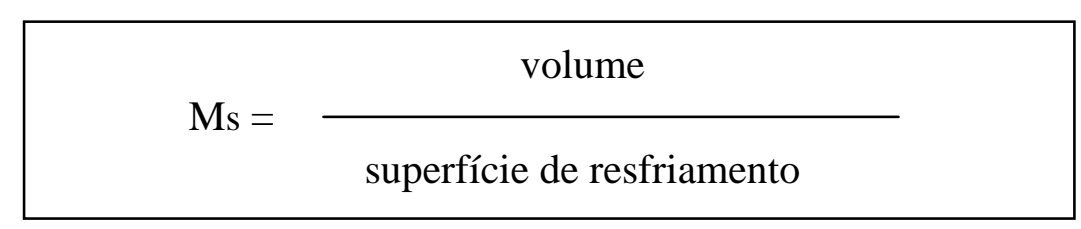


A peça deve ser subdividida em seções geométricas simples e o módulo de cada seção é calculado utilizando-se a expressão anterior. A peça será preenchida adequadamente se a relação entre os módulos de solidificação de duas seções adjacentes for menor que 1,1. Esse preenchimento é utilizado para calcular as condições de resfriamento de toda a peça. Se a peça estiver sendo desenhada num sistema CAD esse cálculo é bastante facilitado pelas condições providas pelo CAD para cálculos de volume e de área.

\subsection{Procedimentos Específicos}

Os procedimentos específicos representam o conhecimento tácito dos engenheiros de fundição relativos às características específicas da geometria das peças, compreendendo as limitações do processo e os procedimentos corporativos estabelecidos pela empresa fabricante.

As limitações impostas pelo processo à forma geométrica das peças podem ser expressas por regras e tabelas que apresentem as diversas faixas de dimensão aceitáveis para determinados "elementos de forma” presentes na peça, como por exemplo as regras que definem as proporções de uma nervura numa peça fundida. Nesse caso, a altura da nervura irá depender do material da peça, do comprimento da nervura e da parede mínima permitida pelo processo de fundição.

Além das limitações ditadas pelo processo de fundição, existem outras estabelecidas pela gerência, que determinam padrões de dimensões, dispositivos standard, etc. para as peças fundidas. Como exemplo, pode ser citado o caso de empresas que reduziram a variedade de medidas para os furos das peças fundidas que passaram a ser escolhi- das dentro de um conjunto preferencial de medidas.

A boa prática de projeto deve ser capaz de satisfazer esses condicionantes, de forma que a peça projetada possa atender a todas as restrições dinamicamente estabelecidas ao longo do detalhamento do projeto.

Não existe uma concordância sobre um conjunto específico de entidades geométricas que representem completamente a prática de fundição. Selecionou-se a seguir as entidades geométricas mais comuns e com valores recomendados na bibliografia (ZUPPAN, 1986; ORLOV, 1986):

- dimensões de nervuras (largura, comprimento e altura);

- parede mínima;

- espessura de seção;

- furo mínimo (diâmetro e comprimento);

- rebaixos (largura e profundidade);

- espessura da parede de furo;

- adoçamentos e conicidades;

- tolerâncias.

A avaliação da fundibilidade de uma peça deve levar em conta esses parâmetros, verificando seu domínio e incorporando no projeto da peça essas restrições.

\section{Dicast - Sistema de Apoio ao Projeto de Peças Fundidas}

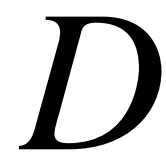

icast é um sistema de auxílio ao projeto de peças fundidas que incorpora os princípios da Engenharia Concorrente na sua formulação. Ele foi construído levando em conta os procedimentos tecnológicos específicos que devem ser considerados no projeto de peças fundidas. Sua implementação foi feita utilizando o sistema FUZZCON, ambiente para desenvolvimento de sistemas de auxílio ao projeto compatível com o sistema operacional Windows 95 (YOUNG, GREEF 
\& O’GRADY, 1992). Consiste num sistema de modelagem e de atendimento a restrições construído sobre o Visual Prolog, com capacidade de aceitar restrições "fuzzy" e com possibilidade de ser conectado a bancos de dados externos, tais como Access e Paradox. A interface com o usuário permite visualizar os domínios das variáveis, os valores instanciados, o valor verdade de cada restrição, a causa das violações às restrições e as recomendações para resolver as inconsistências.

O sistema Dicast compreende um conjunto de variáveis e um conjunto de restrições interligados a elas. Dicast tem três tipos de variáveis: geométricas, tecnológicas e database. As variáveis geométricas estão relacionadas às características específicas dos fundidos tais como: dimensões de nervuras, paredes, furos e adoçamentos. Essas dimensões representam o conhecimento prático encontrado em manuais e livros e são representados e dimensionados nos desenhos. As variáveis tecnológicas estão relacionadas às variáveis geométricas cumprindo o papel de variáveis auxiliares. Sua função é a de classificar determinada variável geométrica numa certa categoria e, a partir daí, associá-la às informações tecnológicas correspondentes. Classes de dimensões, tipos de material, constantes de materiais são alguns exemplos desse tipo de variável. As variáveis do tipo database representam as informações corporativas, isto é, práticas correntes de manufatura da empresa ou ferramentas e dispositivos padronizados utilizados na produção, como por exemplo as brocas e alimentadores disponíveis na ferramentaria. O sistema permite a conexão do mecanismo de inferência com bancos de dados externos, tais como o banco de informações sobre as ferramentas de furar e broquear mantido pela Engenharia de Fabricação da empresa.

A rede de restrições que representa Dicast é mostrada na figura 2. As variáveis se conectam às restrições (representadas em retângulos). 


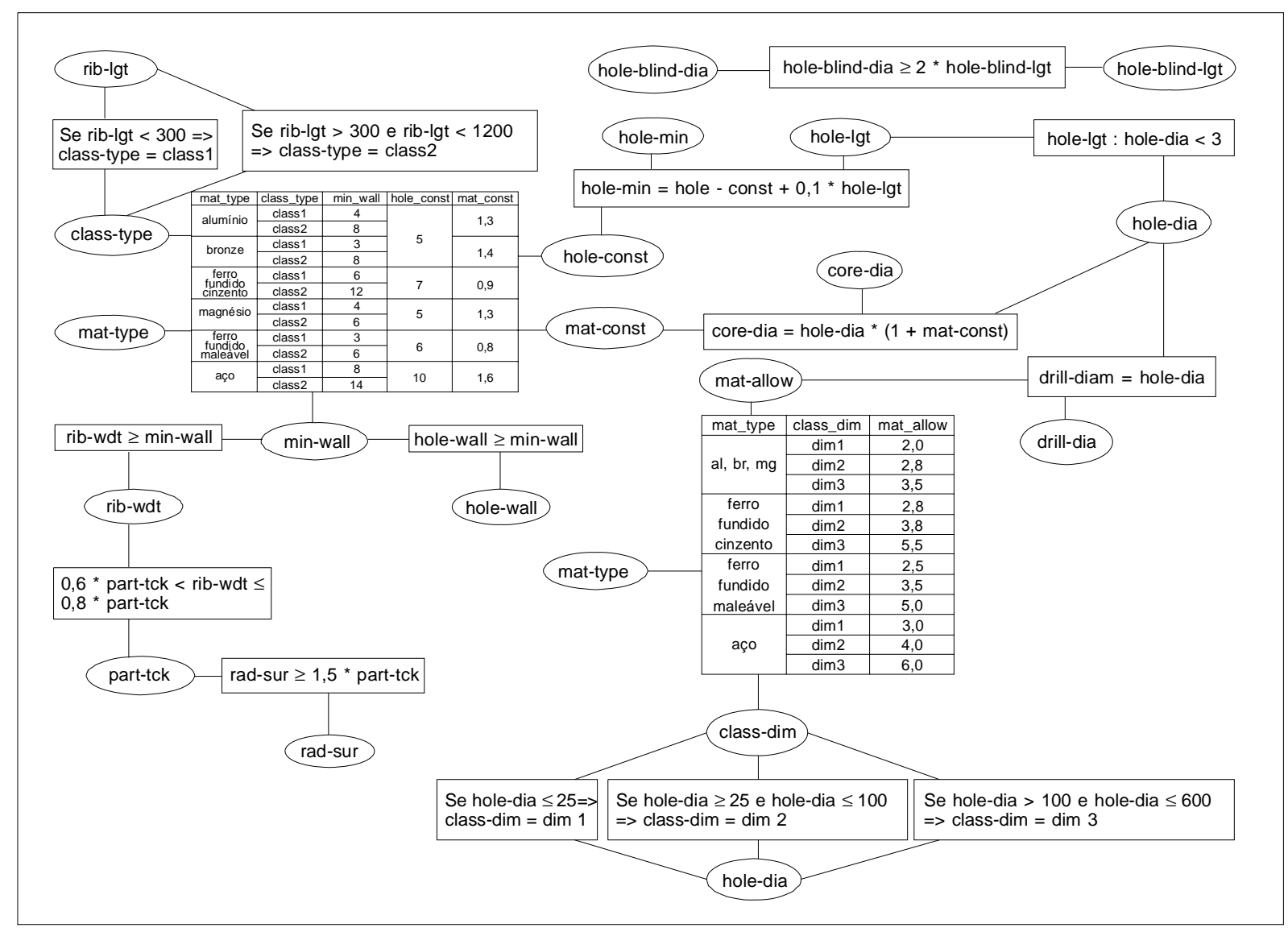

Figura 2 - Rede de restrições associadas ao projeto de peças fundidas

Existem dois tipos de restrições no sistema Dicast: restrições de processo e restrições de classificação. As primeiras expressam as relações entre as variáveis geométricas e expressões matemáticas envolvendo variáveis tecnológicas e geométricas. As últimas são usadas para a formação de grupos baseados em faixas de dimensões das variáveis geométricas e em dados tecnológicos.

A interface do sistema com o usuário é composta de três janelas: janela objetos (variáveis), janela restrições e janela violações (restrições não atendidas). A interface prove uma série de facilidades para definir e representar o domínio de cada variável, as relações entre elas e as restrições que estão conectadas a elas. As restrições e domínios podem ser recuperados pelo editor do programa bastando usar a coluna de botões na janela de objetos.

Para ilustrar a operação do sistema Dicast mostra-se o processo de projeto da peça de ferro fundido desenhada na figura 3. 


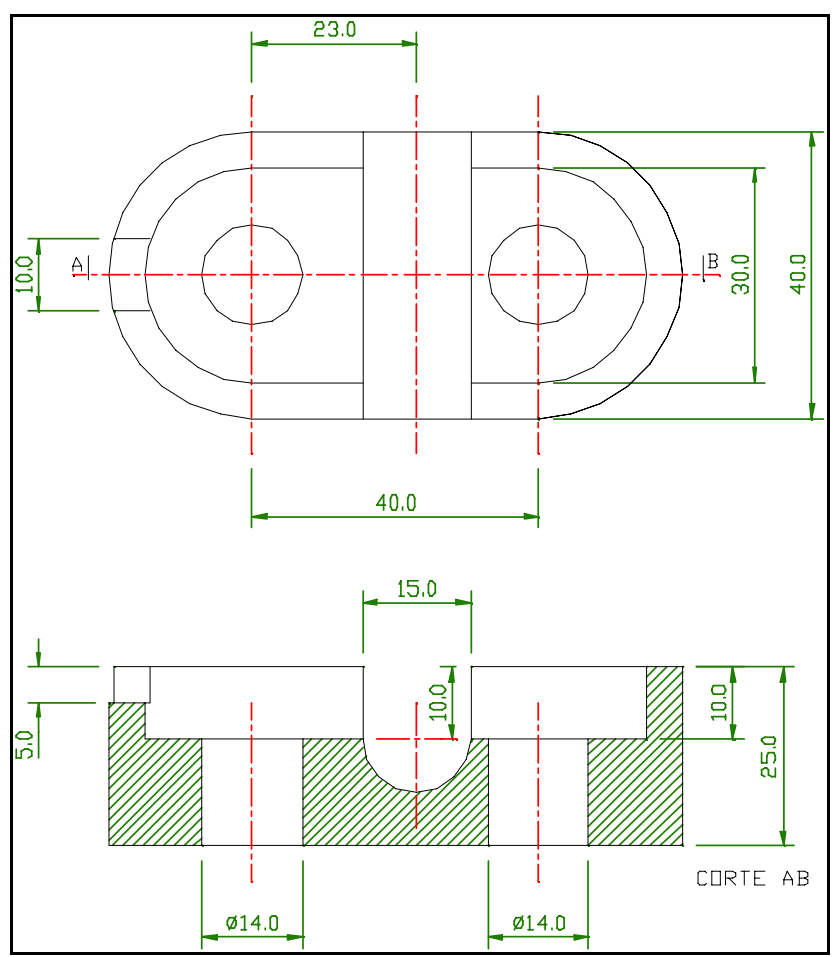

Figura 3 - Exemplo de peça fundida

Inicialmente, o projetista atribui as diversas dimensões aos elementos geométricos da peça e, se estiver desenhando com um programa gráfico 3D, deve proceder à avaliação da solidificação da peça seguindo a rotina de cálculo do módulo de solidificação. Nesse aspecto o uso do programa gráfico é fundamental pela rapidez no cálculo de volumes e pelas facilidades oferecidas para se escrever rotinas de cálculo.

Uma vez aprovada a peça quanto à solidificação, é necessário acionar o sistema
Dicast e carregá-lo com os dados geométricos e tecnológicos referentes à peça. Isso pode ser feito com os dois sistemas ativados - Dicast e programa gráfico - de forma a transferir dados de um para o outro utilizando as facilidades oferecidas pelo ambiente Windows.

A figura 4 mostra o aspecto da interface gráfica do sistema Dicast. As variáveis foram preenchidas com os valores referentes à peça mostrada na figura 3 . 


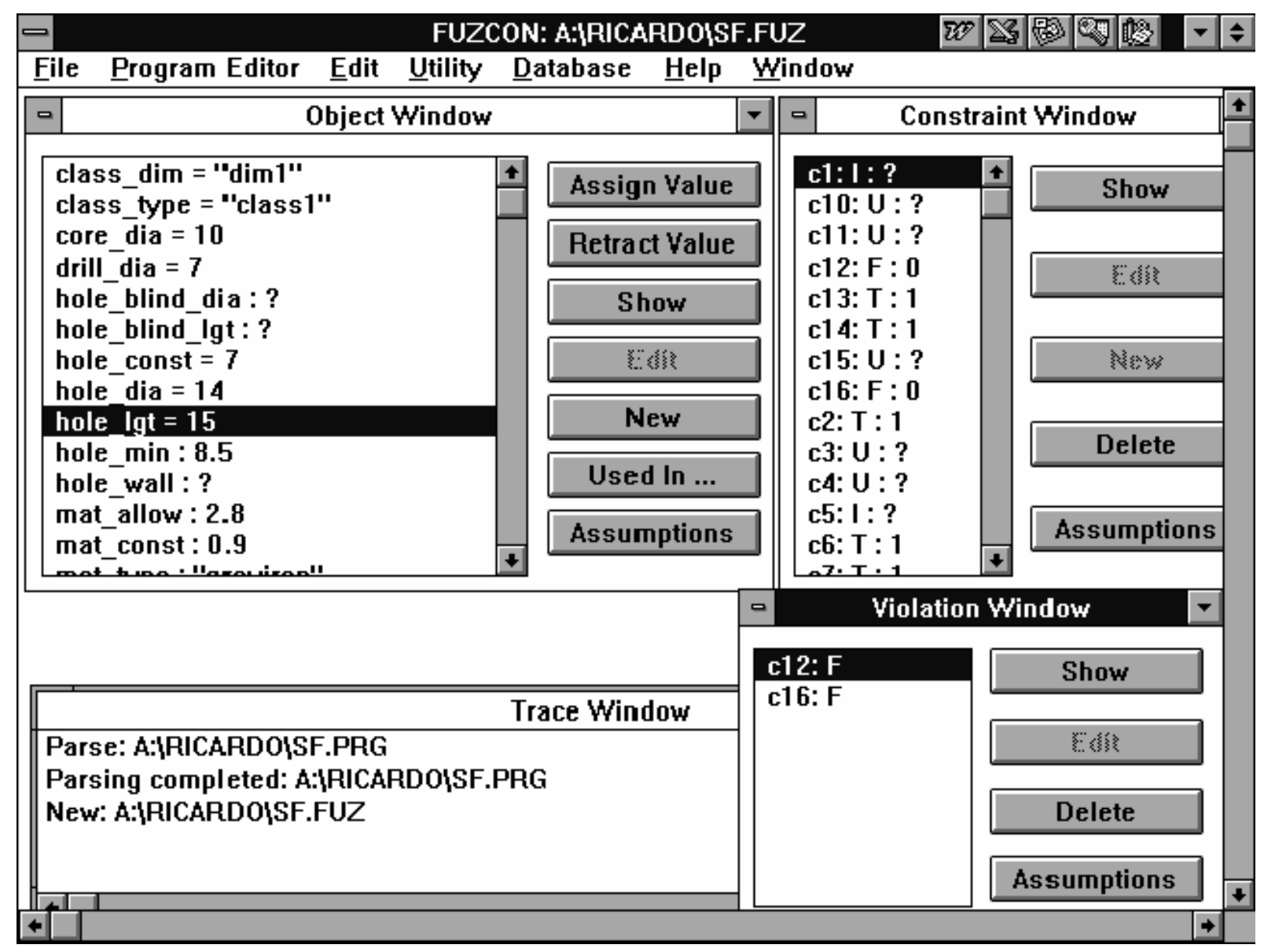

Figura 4 - Interface gráfica do programa Dicast

Após fazer a propagação dos valores atribuídos às variáveis, o sistema retorna o valor verdade das restrições exibindo um código $\mathrm{T}$ ao lado de cada restrição satisfeita pela instanciação. Um código $\mathrm{F}$ aparece ao lado das restrições que não foram atendidas. No exemplo utilizado, a parede da peça é de $5 \mathrm{~mm}$, o que contraria a restrição que estabelece que a menor espessura de parede para uma peça de ferro fundido é de $6 \mathrm{~mm}$. A interface possibilita ainda mostrar a restrição não atendida, na qual pode ser colocada informação textual para auxílio à tomada de decisão do projetista, bastando acionar o botão "show" da janela de violações. No exemplo, caso fosse acionado o botão "show", a restrição c12 apareceria da seguinte forma:

c12:core_dia=hole_dia*(1+mat_const)

Além dos códigos $\mathrm{T}$ e $\mathrm{F}$ aparece um código I ao lado das restrições que são irrelevantes para o exemplo em estudo e um código U para as restrições indeterminadas.

\section{Conclusões}

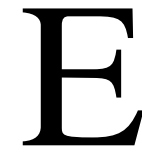

sse artigo demonstra ser possível construir um sistema capaz de realçar o processo decisório do projetista, dando-lhe assistência nas diretrizes básicas deste processo e possibilitando-lhe uma avaliação da manufaturabilidade ao longo da progressão do projeto. Além disso, a facilidade de conexão com bancos de dados 
externos oferecida pelo sistema permite que o ato de projetar se dê em concordância com os padrões de determinada empresa.

O desenvolvimento do sistema Dicast seguiu o critério de dar assistência ao projetista ao invés de tomar decisões no lugar dele. Seu desenvolvimento se orientou no sentido de aproveitar os bancos de dados já existentes na empresa e usar programas comerciais de bancos de dados e de CAD, ao invés de criar bancos de dados restritos ao sistema ou desenvolver sistemas CAD específicos baseados em primitivas geométricas características do processo de fundição (LUBY et alli, 1986). Nesse sentido, o sistema tirou vantagem da capacidade de conexão com bancos de dados externos proporcionada pelo ambiente FUZZCON. O conhecimento prático expresso pelas tabelas mostradas na rede de restrições pode ser ampliado para todos os materiais padronizados e armazenado em um banco de dados externo.

Foi mostrada, com este exemplo elaborado para o projeto de peças fundidas, a transformação de conhecimentos factuais e conhecimentos na forma de procedimentos em agentes dinâmicos capazes de responder a inferências. Esses conhecimentos que se encontram espalhados em manuais e livros de forma estática podem ser manipulados computacionalmente e iterativamente, constituindo-se num supervisor dotado de uma memória ampliada sobre os condicionantes do projeto de uma peça fundida. Nesse sentido, sistemas como esse podem ser utilizados como instrumento para o ensino tecnológico, como por exemplo o treinamento on the job de projetistas.

Finalizando, desenvolvimentos futuros desse trabalho vão depender de aperfeiçoamentos do ambiente Windows no sentido dele tornar-se de fato um ambiente multitarefa capaz de suportar processamento paralelo de programas gráficos e programas tecnológicos capazes de condicionar os parâmetros gráficos. Nesse novo ambiente computacional tarefas feitas seqüencialmente passam a ser feitas simultaneamente, possibilitando uma avaliação integrada de todas as restrições que condicionam a geometria de uma peça fundida.

\section{Agradecimentos}

Este trabalho foi realizado com o apoio de uma bolsa de pós-doutorado da CAPES e do Departamento de Engenharia Industrial da Universidade Estadual da Carolina do Norte, local de trabalho do Prof. Peter O’Grady até 1996.

\section{Referências Bibliográficas:}

AKIN O.: Psychology of Architectural Design, Pion, London, 1986.

BUCCIARELLI L.: “An ethnographic perspective on engineering design”. Design Studies, vol. 9, n .3, Butterworth, Surrey, pp. 159-168, 1988.

CLAUSING D.: “Concurrent Engineering”. Proceedings of the Winter Annual Meeting, A.S.M.E., San Francisco, 1989.

GOEL V. \& PIROLLI P.: "Design within Information-Processing Theory: The Design Problem Space”. A.I. magazine, vol. 10, n .1, spring 89, American Association for Artificial Intelligence, U.S.A., pp. 19-36, 1989.
HINRICKS T.: Problem Solving in Open Worlds: a case study in design, Lawrence Erlbaum, New Jersey, 1992.

LIAU J.: A Multi-Valued Logic Based Constraint Modeling System for Concurrent Engineering, Phd dissertation, Department of Industrial Engineering, North Carolina State University, Raleigh, 1994.

LUBY S.C.; DIXON J.R. \& SIMMONS M.K.: "Designing with Features: Creating and Using a Features Data Base for Evaluation of Manufacturability of Castings". Proceedings of the ASME Computers in Engineering Conference, Chicago, 1986. 
MILES J. \& MOORE C.: Practical KnowledgeBased Systems in Conceptual Design, SpringerVerlag, Great Britain, 1994.

NAVEIRO R. \& O'GRADY P.: “A Concurrent Engineering Approach for Design Assistance of Casting Parts". Proceedings of the 1995 International Conference on Engineering Design, ICED 95, WDK, Praha, pp. 922-927, 1995.

NAVEIRO R.: “The Role of Computer Support for Integrated Product Development”. Proceedings of the 1997 International Conference on Engineering Design, ICED 97, WDK, Tampere, vol. 3, pp. 465-468, 1997.

NEWELL A. \& SIMON H.A.: Human Problem Solving, Prentice-Hall, New Jersey, 1972.

O'GRADY \& YOUNG R.: "Issues in Concurrent Engineering”. Journal of Design and Manufacturing, vol.1, n .1, Chapman \& Hall, Great Britain, pp. 27-34, 1991.

ORLOV P.: Fundamentals of Machine Design, Mir Publishers, Moscow, 1986.

PARSAEI H. \& SULLIVAN W.: "Principles of Concurrent Engineering”. Concurrent Engineering, Parsaei H. and Sullivan W. (ed.), Chapman \& Hall, London, pp. 3-23, 1993.
WHITNEY D.: "Integrated Design and Manufacturing in Japan”. Manufacturing Review, vol.6, n .4, A.S.M.E., U.S.A., 1993.

WLODAVER R.: Directional Solidification od Steel Castings, Pergamon Press, London, 1966.

WOODBURY R.F.: "Strategies for Interactive Design Systems”. Computability of Design, Kalay, Y.E. (ed.), Wiley, New York, pp. 11-36, 1987.

YOUNG R.; GREEF A. \& O'GRADY P.: “An artificial intelligence-based contraint network system for concurrent engineering”. International Journal of Production Research, Taylor \& Francis, London, vol.30, n .7, pp. 1715-1735, 1992.

ZANGWILL W.: “Concurrent Engineering: Concepts and Implementation”. I.I.E.E. Engineering Management Review, winter 1992/93, vol.20, n .4, pp. 40-52, 1992.

ZUPPAN E.C.: “Castings made in sand molds". Handbook of Product Design for Manufacturing, Bralla J. (ed.), McGraw-Hill, New York, 1986.

\section{DICAST: AN INTELLIGENT SYSTEM TO ASSIST THE DESIGN OF CASTING PARTS}

\section{Abstract}

This paper addresses the issue of integrating design and manufacturing by describing a Concurrent Engineering system called Dicast that has been developed to assist designers with the detailed design of castings. Design is viewed as a constraint driven activity where designers negotiate solutions to the design based on dynamically evaluating constraints. In this way, the design process can be modeled as variables that represent design parameters interconnected with constraints. Advice is given to the designer when constraints are violated. 